\title{
Identificação da análise de marcas de mordida em odontologia forense: uma revisão
}

\section{da literatura}

\author{
Identifying bite mark analysis in forensic dentistry: a literature review \\ Análisis de las marcas de mordida en odontología forense: una revisión de la literatura
}

Recebido: 22/10/2021 | Revisado: 29/10/2021 | Aceito: 03/11/2021 | Publicado: 05/11/2021

\author{
Mariana Vieira Melo \\ ORCID: https://orcid.org/0000-0003-4458-4485 \\ Centro Universitário de Patos de Minas, Brasil \\ E-mail: marianamelo@unipam.edu.br \\ Larissa Cristina Pereira Costa \\ ORCID: https://orcid.org/0000-0002-9609-2549 \\ Centro Universitário de Patos de Minas, Brasil \\ E-mail: larissacosta@unipam.edu.br \\ Rafael Martins Afonso Pereira \\ ORCID: https://orcid.org/0000-0002-1085-0813 \\ Centro Universitário de Patos de Minas, Brasil \\ E-mail: rafaelmap@unipam.edu.br \\ Fabrício Campos Machado \\ ORCID: https://orcid.org/0000-0003-4603-8795 \\ Centro Universitário de Patos de Minas, Brasil \\ E-mail: fabriciocampos@unipam.edu.br \\ Victor da Mota Martins \\ ORCID: https://orcid.org/0000-0001-6631-6161 \\ Centro Universitário de Patos de Minas, Brasil \\ E-mail: victor.mota@unipam.edu.br \\ Aletheia Moraes Rocha \\ ORCID: https://orcid.org/0000-0003-1650-7546 \\ Centro Universitário de Patos de Minas, Brasil \\ E-mail: aletheiamoraes@unipam.edu.br
}

\begin{abstract}
Resumo
A Odontologia Forense é uma área das ciências forenses responsável por ajudar a justiça principalmente nos casos de identificação humana. As técnicas de identificação remontam desde a época de 49 DC, e seu uso vem sendo relatado ao longo da história. A análise através das marcas de mordida é uma técnica complexa e que traz muitas subjetividades, dividindo opiniões e gerando muitas controvérsias. O presente trabalho consiste de uma revisão de caráter narrativo e discute como é feita a identificação através das marcas de mordida, destacando sua importância e suas limitações, apontando também o papel do cirurgião-dentista. Foi realizada uma busca nas bases de dados "PubMed", "Scielo", e "Lilacs" dos últimos 20 anos utilizando os descritores em português: "Mordida Humana", "Odontologia Forense", "Mordida" e em inglês "Bite Human", "Forensic dentistry" e "Bite". Essas marcas são encontradas principalmente em crimes de abuso sexual, homicídio e negligencia infantil, onde o criminoso utiliza os dentes como arma, deixando uma marca sobre a pele da vítima ou em objetos deixados na cena do crime. Partindo do princípio de que a arcada dentaria é única para cada ser humano, é feita uma comparação entre a marca deixada no local com a dentição do suspeito, podendo incriminar o indivíduo. Diante disso, conclui-se que as marcas de mordida podem ser uma importante ferramenta na resolução de crimes, desde que realizada de maneira criteriosa, por profissionais qualificados e respeitando suas limitações.
\end{abstract}

Palavras-chave: Mordida humana; Odontologia Forense; Mordida.

\begin{abstract}
Forensic dentistry is an area of forensic science charged with assisting justice primarily in cases of human identification. Identification techniques date back to $49 \mathrm{AD}$, and their use has been recorded throughout history. Bite mark analysis is a complex technique that carries with it many subjectivities, dividing opinions and generating much controversy. This article consists of a narrative literature review and discusses how the identification of bite marks is performed, highlighting its importance and limitations, also pointing out the role of the dentist. A search was conducted in the databases "PubMed", "Scielo" and "Lilacs" during the last 20 years using the descriptors in portuguese: "Mordida Humana", "Odontologia Forense", "Mordida" and in english: "Bite Human", "Forensic dentistry" and "Bite". These marks are mainly found in crimes of sexual abuse, murder, and child abandonment, where the offender uses his teeth as a weapon, leaving a mark on the victim's skin or on objects left at the scene of the
\end{abstract}


crime. Based on the principle that the dental arch is unique to each human being, a comparison is made between the mark left at the crime scene and the dentition of the suspect, which may incriminate the individual. Therefore, it is concluded that bite marks can be an important tool in solving crimes, provided that they are performed in a judicious manner, by qualified professionals and respecting their limitations.

Keywords: Bite human; Forensic dentistry; Bite.

\section{Resumen}

La odontología forense es un área de la ciencia forense encargada de ayudar a la justicia principalmente en casos de identificación humana. Las técnicas de identificación se remontan al año 49 d.C., y su uso se ha registrado a lo largo de la historia. El análisis de las marcas de mordedura es una técnica compleja que conlleva muchas subjetividades, dividiendo opiniones y generando mucha controversia. Este artículo consiste en una revisión bibliográfica y discute cómo se lleva a cabo la identificación de las marcas de mordida, destacando su importancia y limitaciones, señalando también el papel del cirujano dental. Se realizó una búsqueda en las bases de datos "PubMed", "Scielo" y "Lilacs" durante los últimos 20 años utilizando los descriptores en portugues: "Mordida Humana", "Odontologia Forense", "Mordida" y inglés: "Human Bite", "Forensic Dentistry" y "Bite". Estas marcas se encuentran principalmente en los delitos de abuso sexual, asesinato y abandono de niños, en los que el delincuente utiliza sus dientes como arma, dejando una marca en la piel de la víctima o en los objetos dejados en la escena del crimen. Basándose en el principio de que la arcada dental es única en cada ser humano, se realiza una comparación entre la marca dejada en la escena del crimen y la dentición del sospechoso, que puede incriminar al individuo. Por lo tanto, se concluye que las marcas de mordedura pueden ser una herramienta importante en la resolución de delitos, siempre que se realicen de forma juiciosa, por profesionales cualificados y respetando sus limitaciones.

Palabras clave: Mordedura humana; Odontología forense; Mordedura.

\section{Introdução}

A Odontologia Legal tem um papel crucial na identificação humana na qual, desde a época de 49 DC, houve o relato de que os dentes foram usados para fazer o reconhecimento de um corpo (Divakar, 2017). Ela representa a relação entre a biologia e o direito, uma vez que o propósito dessa área é colocar a ciência à disposição da justiça (Almeida; Paranhos \& Silva, 2010). Trata-se de uma área importante da ciência forense onde o cirurgião-dentista usa sua experiência e conhecimento técnico a favor da justiça, podendo atuar em casos de identificação de restos mortais em acidentes, avaliação de traumas nos tecidos bucais e também em testemunhos sobre negligência odontológica (Verma; Kumar \& Bhattacharya, 2013).

A Odontologia Legal é um ramo que tem crescido consideravelmente e adquirido uma relevância cada vez maior dentro do sistema judiciário (Divakar, 2017). Dentro dos processos forenses, a identificação humana é uma prática comprovada e validada cientificamente, porém a análise por meio de marcas de mordida ainda é um método que apresenta alto grau de complexidade e subjetividade (Verma; Kumar \& Bhattacharya, 2013). A análise através das marcas de mordida é uma ferramenta de identificação que pode ser usada para vincular um suspeito ao local do crime, comparando a dentição do agressor com as marcas deixadas na vítima, em objetos ou alimentos (Coutinho, 2013).

No entanto, existem alguns fatores que dificultam a utilização das marcas de mordida em investigações criminais, como por exemplo, as distorções causadas pela curvatura e o grau de elasticidade da pele, e os edemas que se formam no local após a agressão (Bhagat, 2018). Desta forma, essa análise acaba sendo, por diversas vezes contestada, dividindo opiniões entre os autores. Alguns sustentam que a técnica é eficaz, e pode ser usada nos processos forenses (Nascimento et al., 2012). Outros autores, no entanto, questionam a individualidade das marcas de mordidas e preconizam seu uso apenas para a inclusão ou exclusão de suspeitos (Tuceryan et al., 2011).

Sobretudo, o fato é que as taxas de homicídio e de violência doméstica são crescentes na sociedade, sendo comum encontrar ferimentos por mordida nas vítimas, que em sua maioria são mulheres e crianças (Amorim et al., 2016). Em casos onde existem provas consistentes com detalhes suficientes, essa análise pode se tornar uma poderosa ferramenta de auxílio, apontando ou excluindo sujeitos durante as investigações (Nadal et al., 2015).

Contudo, não bastam apenas provas, é preciso um profissional qualificado para usá-las de forma correta. Segundo Mattos (2021) é função do profissional odontolegista, reconhecer as marcas de mordida e coletar os dados o mais rápido 
possível. Ficando evidente a importância do cirurgião-dentista para auxiliar nos processos de identificação humana, principalmente no que se refere aos estudos dos padrões das marcas de mordida.

Portanto, esse trabalho fornece uma revisão narrativa da literatura, e tem como objetivo, discutir como é realizada a identificação humana por meio das marcas de mordida, qual sua importância e suas limitações, demonstrando também a importância do cirurgião-dentista qualificado nas equipes de investigação criminal.

\section{Metodologia}

O presente estudo trata-se de uma revisão de caráter narrativo e para sua realização foi feita uma busca nas bases de dados "PubMed", "Scielo", e "Lilacs" de artigos publicados nos últimos 20 anos, durante o período de 2001 à 2021, nos idiomas inglês e português. Foram utilizados os descritores "Mordida Humana", "Odontologia Forense" e "Mordida" e esses mesmos termos também na língua inglesa: "Bite Human", "Forensic dentistry" e "Bite", com o auxílio do operador boleano AND. Chegou-se ao resultado de 265 artigos, destes 225 foram excluídos por se tratar de artigos duplicados, artigos de outros idiomas, aqueles que não possuíam resumo disponível, teses, dissertações, monografias, trabalhos de conclusão de curso e os artigos que trazem marcas de mordidas não provocadas por humanos Restando portanto, 40 artigos que foram utilizados para a confecção deste trabalho (Figura 1).

Figura 1: Fluxograma do processo de seleção dos artigos.

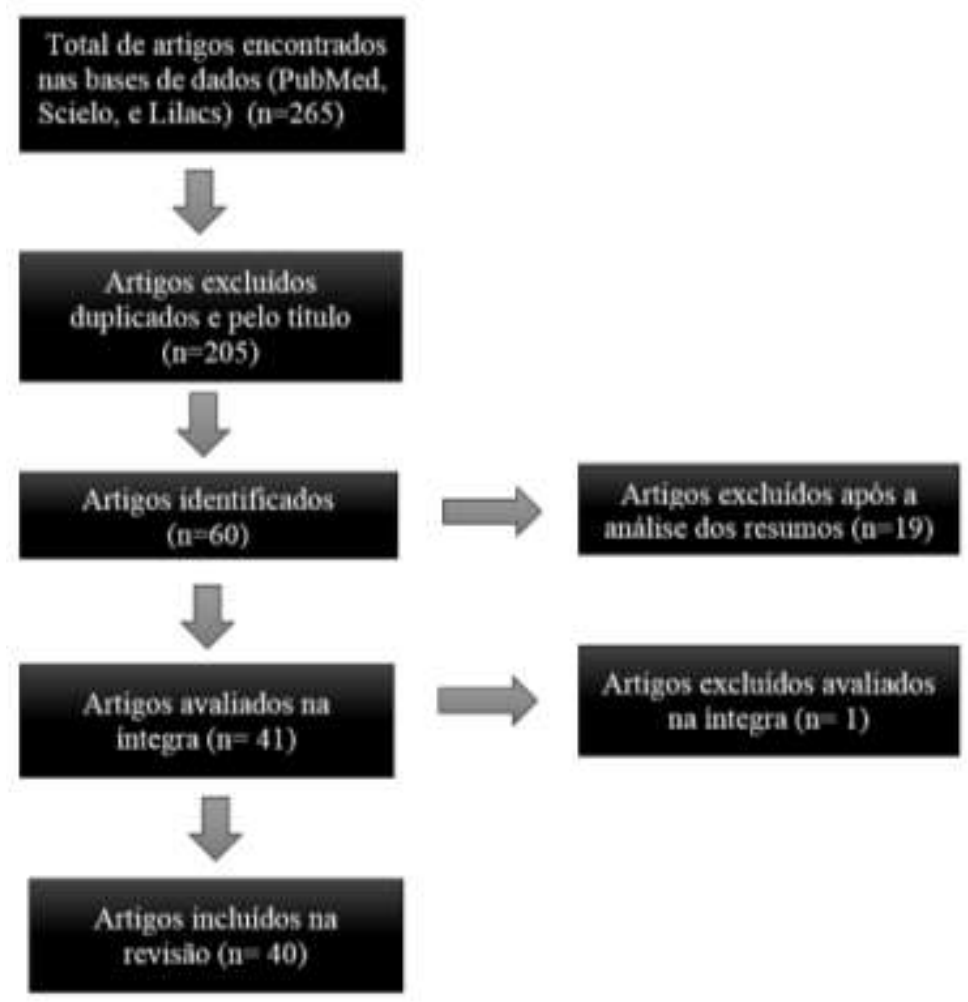

Fonte: Autores.

\section{Resultados e Discussão}

\subsection{Uma breve visão histórica}

A Odontologia Forense é uma ciência que está em constante evolução, e suas técnicas de identificação humana através dos dentes, vem sendo relatadas ao longo da história. A primeira utilização data do ano 49 DC, com os casos de 
Agripina e Lollia Paulina, onde o corpo de Lollia foi identificado devido às características distintas que sua dentição possuía (Kaleelullah \& Hamid, 2020).

A primeira identificação feita por um dentista foi em 1776 pelo Dr. Paul Evere. Ele havia confeccionado uma prótese em marfim para Warren, que foi morto em uma batalha em Boston, e seu corpo foi identificado por Paul graças à prótese que ele usava (Divakar, 2017). Em 1983 no Reino Unido, uma mordida em um pedaço de queijo, foi a responsável por condenar um assassino de três membros de uma família (Hinchliffe, 2011).

Em 1971, na França, o incêndio da Scandinavian Star foi um dos piores desastres de balsa do mundo. E a odontologia forense conseguiu ajudar em 107 casos, realizando a identificação dentária dos passageiros que estavam a bordo (Shah et al., 2019).

Em 1870, Ansil Robinson era o principal suspeito de matar sua amante, Mary Lunsford, e como a vítima apresentava lesões por mordedura nos braços, essas marcas foram usadas como evidência, em uma tentativa de compará-las aos dentes de Robinson (Shah et al., 2019).

No ano de 1972, as marcas de mordida em pele humana foram usadas para identificar o agressor no caso Regina contra Boden, "o vampiro estuprador" (Mânica, 2016). Anos depois, em 1978, o famoso serial killer Ted Bundy conseguiu ser identificado graças ao trabalho da odontologia forense, usando a comparação das marcas presentes na vítima com os moldes dos dentes do acusado (Riaud, 2014).

\subsection{Quando a odontologia e a justiça se interconectam}

É dever do estado proteger a integridade anátomo-funcional do ser humano, e para garantir isso, a justiça lança mão de várias ferramentas, e uma delas é a Odontologia Legal. Através de perícias odontológicas, os profissionais odontologistas coletam dados e elaboram relatórios técnicos que posteriormente são utilizados nos tribunais (Amorim et al., 2016).

A odontologia Legal é o ramo da odontologia que envolve o processamento, revisão, avaliação e apresentação de evidências odontológicas, amparando os processos judiciais com dados científicos e objetivos. O odontolegista é o profissional que detém conhecimento para analisar e interpretar os registros odontológicos, e assim identificar um indivíduo e fornecer às autoridades os dados precisos para apurar casos de negligência, fraude ou abuso (Ata-Ali \& Ata-Ali, 2014).

Os profissionais odontolegais possuem conhecimento especializado, podendo esclarecer questões tanto no âmbito criminal, como administrativo e civil. Eles atuam nos processos de identificação humana (tanto em vivos quanto em cadáveres), estimativa de idade, estatura, raça, danos estéticos e funcionais, e também podem atuar no reconhecimento de lesões produzidas por mordidas (Amorim et al., 2016).

\subsection{Odontologia forense}

Dentro da Odontologia Forense existem diferentes métodos de identificação que podem ser aplicados, como: impressões de dentes, rugoscopia, queiloscopia, análise de DNA dental, radiografias e análise por meio de marcas de mordida (Shah et al., 2019).

A rugoscopia é uma técnica que estuda o padrão das rugosidades palatinas, analisando sua forma, quantidade, direção e tamanho (Ata-Ali \& Ata-Ali, 2014). Já a queiloscopia, envolve o estudo das formas, depressões e elevações das impressões labiais (Chugh \& Narwal, 2017). O DNA também pode ser utilizado em alguns casos, afinal ele está presente no sangue e também na saliva, sendo assim, durante o processo de mordida a saliva pode ser depositada sobre a pele ou objeto, e quando presente em quantidades suficientes, pode revelar a identidade genética do suspeito (Zapico \& Menéndez, 2016). 
Quando disponíveis, os registros radiográficos podem ser utilizados para a identificação humana, como por exemplo nos desastres em massa. As radiografias pré-morte de um indivíduo são comparadas com os registros pos mortem, revelando uma identidade para aquele corpo (Kaleelullah \& Hamid, 2020).

As marcas de mordida são utilizadas para comparar a dentição de um suspeito com o ferimento da vítima, tendo como base o pressuposto da unicidade da arcada. Porém, dentre todas as técnicas que foram expostas, essa é a que gera mais conflito de opiniões, principalmente devido à análises errôneas que já foram cometidas (Franco et al., 2015).

\subsection{Marcas de mordida}

A análise através de marcas de mordida apesar de ser uma prática bem estabelecida e validada cientificamente, é a mais controversa, dividindo opiniões de autores e sendo motivo de grandes debates (Pretty, 2008). Ela é utilizada para comparar a lesão presente na vítima com a dentição do suspeito a fim de encontrar o verdadeiro criminoso (Dama et al., 2020).

A American Board of Forensic Odontology (ABFO) define a mordida humana como uma marca semicircular que compreende dois arcos separados por uma área central sem lesão, e suas periferias podem vir acompanhadas de abrasões, contusões e/ou lacerações que mostram a dimensão, a forma e o lugar das superfícies de contato da dentadura humana (Pretty, 2008). Elas são comumente encontradas em casos de agressão sexual, abuso infantil, violência doméstica, homicídios e também em situações de defesa (Amorim et al., 2016).

Os agressores muitas vezes mordem como uma expressão de domínio ou raiva. Em contrapartida, a vítima desfere esse ato como uma forma de lutar pela sobrevivência. Sendo assim, as lesões em mulheres são mais frequentemente encontradas nos seios e porções genitais enquanto nos homens são mais comuns nos braços e ombros (Sweet \& Pretty, 2001).

Amorim et al. (2016) descreveram a prevalência de marcas de mordida em vítimas de violência periciadas no Instituto Médico Legal de Feira de Santana (BA) por meio de laudos arquivados nesse local durante os anos de 2007 até 2014. Das 1045 perícias caracterizadas como violência, 32 apresentavam lesões de mordida humana, e destas, 78,1\% eram mulheres, em grande parte vítimas de violência doméstica. $\mathrm{O}$ estudo também concluiu que as marcas de mordida foram predominantes na região de cabeça e pescoço e membros superiores.

Dessa forma, nota-se que as marcas de mordida servem como evidências criminais, podendo ser encontradas sobre a pele das vítimas. Elas são afetadas pelo tipo, número e peculiaridades dos dentes, dinâmica de oclusão, função muscular, movimento dentário individual e disfunção da articulação temporomandibular (Pallam et al., 2016).

Portanto, quando um indivíduo morde, os dentes são reproduzidos sobre uma determinada superfície, revelando uma identidade naquela marca (Araújo, 2019). Essas marcas também podem ser encontradas em alimentos como pedaço de queijo, chocolate, (Mânica, 2016) e também em objetos, ou outras substâncias espalhadas pela cena do crime como madeira, couro, etc (Hinchliffe, 2011).

Essa análise é baseada no princípio da unicidade da arcada, ou seja, não existem dois indivíduos com o mesmo perfil oclusal, podendo ser equiparada a uma impressão digital ou ao DNA (Shah et al., 2019). Distâncias, angulações, falhas, processos restauradores entre os dentes são algumas características que tornam cada arcada exclusiva (Verma; Kumar \& Bhattacharya, 2013).

\subsection{Análise das marcas de mordida}

De acordo com padrões pré-estabelecidos, existem etapas a se seguir durante uma investigação. O primeiro passo quando o perito encontra uma marca de mordida é verificar se pertence a um humano, a um animal ou se existe a possibilidade de ter sido autoinfligida (Mânica, 2016). Geralmente, mordidas causadas por animais tem uma característica de rasgo, causando lacerações na pele. A distância intercanina, a disposição dos dentes, (Kashyap et al., 2015) e alinhamento do arco 
também difere do ser humano. Além disso, mordidas de animais costumam causar uma ferida de maior profundidade (AVON, 2004).

Quando o profissional forense se depara com uma marca de mordida seja ela em pele ou alimento, deve-se fazer uma descrição detalhada, evidenciando o local, a cor, posição anatômica, o formato e o tipo da lesão. Também deve haver o registro das evidências coletadas da vítima que incluem exame intra e extra-oral, fotografias e coleta de saliva (DNA), moldagem dos arcos e registro da mordida em cera. E da mesma forma, a coleta de dados também deve ser feita no suspeito (Sweet \& Pretty, 2001).

Durante essa coleta, os registros fotográficos são cruciais e devem ser feitos de uma forma precisa, seguindo técnicas corretas. Isso requer um conhecimento dos princípios de captura de imagem, incluindo os recursos da câmera, suas limitações, e também outros equipamentos que podem ajudar na tarefa (Golden, 2011). Uma técnica padrão deve seguir alguns princípios básicos como Golden (2011) descreveu:

- As fotos devem ser capturadas de três a cinco metros e ter informações suficientes no quadro para que seja possível ver em qual local do corpo a mordida se localiza.

- Apesar de não ser obrigatório, é recomendado que se inclua uma escala na imagem.

- A câmera deve ser posicionada perpendicularmente para minimizar a distorção angular.

- Afixar etiquetas (em um local que não interfira na medição) contendo o número do processo, nome da vítima, agência, data e as iniciais ou nome do fotógrafo.

- Resolução grande o suficiente para que a foto possa ser ampliada em proporções reais, sem perda de detalhes.

- Fotos nas duas versões: preto e branco e colorida. Pois a foto em preto e branco pode conter alguns detalhes que podem passar despercebidos. Hoje em dia com as câmeras digitais, é necessário apenas uma imagem, e os dois formatos podem ser obtidos em um programa de edição de imagem.

- As fotos com infravermelho também podem ser úteis pois mostram a parte mais profunda do padrão de hematoma, na derme e no tecido vascular subjacente.

Além das fotografias, a coleta de saliva do local também é necessária, pois dentre todos os fluidos corporais, ela representa o mais fácil obtenção devido à pronta disponibilidade, além dos métodos de coleta serem não invasivos e de menor custo, podendo ainda revelar o perfil genético do agressor (Kapoore \& Chowdhry, 2018). Todavia, essa coleta deve ser feita de maneira rápida devido à alta perecibilidade da amostra. A técnica de coleta é realizada por meio do suabe duplo, onde o primeiro é molhado em água destilada e usado para lavar o local que entrou em contato com a língua, e o segundo é usado seco, para coletar a umidade do primeiro suabe. Os dois devem secar em temperatura ambiente por no mínimo 45 minutos, e só depois entregue para os testes (Sweet \& Pretty, 2001).

O protocolo de análise para a comparação é feito em duas fases: análise métrica e análise padrão. A primeira se refere às mensurações de locais específicos, como distância intercanina, espaço entre as marcas dos dentes, indicações de mau posicionamento, etc. A segunda, se refere à associação padrão, onde o principal instrumento é a sobreposição das imagens (Amorim, 2016).

Essa associação pode ser obtida por métodos clássicos como a sobreposição direta ou indireta do modelo dos dentes do suspeito sobre a impressão da marca de mordida, coloração, achados radiográficos ou polvilhado. Já nos métodos modernos, encontram-se as sobreposições assistidas por computador, que vem demonstrando uma eficácia e um nível de confiabilidade bem maior que os métodos clássicos (Pallam et al., 2016).

De acordo com a ABFO, após a análise, pode-se chegar a cinco possíveis resultados, baseando-se na quantidade de características compatíveis entre o suspeito e a impressão da mordida (Pretty \& Hall, 2002), sendo eles:

1- identificação positiva: o suspeito é identificado como o agressor; 
2- provável identificação: é mais provável que o suspeito tenha sido o causador daquela marca;

3- possível identificação: não é exclusivo, porém não há detalhes suficientes, a marca pode ter sido causada por outra pessoa;

4- inconclusivo: não existem evidências suficientes para estabelecer uma ligação entre o suspeito e a marca de mordida;

5- identificação negativa ou exclusão: existem discrepâncias entre a impressão e a dentição do suspeito, excluindo a possibilidade do indivíduo tê-la produzido.

\subsection{A importância da análise das marcas de mordida}

A taxa de criminalidade é algo ascendente em nossa sociedade. Mesmo dispondo de tantas tecnologias, a identificação de um criminoso ainda é uma tarefa árdua. A investigação criminal necessita da junção de todas as evidencias possíveis para chegar a um resultado confiável (Kaleelullah \& Hamid, 2020). A análise por marcas de mordida pode ajudar o sistema judicial a responder questões cruciais sobre a cena do crime (Verma; Kumar \& Bhattacharya, 2013).

É fato que, nem toda marca de mordida apresentará detalhes suficientes para que possa ser utilizada como indício, pois o número detalhes registrados na pele varia em cada caso, porém, nos cenários onde essas minúcias existem, a identificação das marcas pode ser extremamente válida, ligando ou excluindo suspeitos, principalmente nos casos de abuso físico, sexual e homicídios (Sweet \& Pretty, 2001). Crimes estes, que são de natureza grave e brutal, e em algumas situações a marca pode ser a única evidência disponível, o que torna o serviço do dentista forense de extrema responsabilidade (Whittaker, 2004).

Esse método de análise também pode ajudar nos casos de negligência infantil, como Weeratna destacou em 2014. Ele citou o caso clínico de uma criança de três anos que apresentava 42 lesões pelo corpo. Os pais procuraram atendimento e, de início, os profissionais que atenderam confundiram com lesões dermatológicas e queimaduras. Após investigação, encaminharam o paciente para um especialista que constatou que as marcas eram compatíveis com a dentição da irmã mais velha, a qual confessou.

Com base nesse exemplo, nota-se a necessidade de os profissionais da saúde reconhecerem tais marcas, já que muitas vezes são eles que fazem o primeiro contato com a vítima, de forma a realizarem um correto encaminhamento ao especialista em Odontologia Forense, que provavelmente conseguirá elucidar o caso (Weeratna, 2014).

\subsection{Limitações da técnica}

A análise com base nas marcas de mordida, encontra alguns obstáculos. Mesmo havendo uma variação de perfis oclusais em cada ser humano, diferentemente do DNA, ela não é constante ao longo da vida, não sendo possível criar um banco de dados (Kaleelullah \& Hamid, 2020). Além disso, a pele não é um bom local para armazenar uma impressão, afinal ela não é plana, havendo distorções, que podem ser causadas no momento da luta entre vítima e agressor; ou ainda durante a realização de fotografias, caso as técnicas utilizadas não forem adequadas (Whittaker, 2004); e também podem ser distorcidas pelo movimento postural da vítima após o ataque (Bush, 2009).

Os edemas e as hemorragias que se formam no local após a agressão, também acabam se tornando um fator limitante, em razão da desidratação e dos fenômenos de putrefação que causam mudanças no local (Figueira Junior \& Moura, 2014). Na maioria das vezes as marcas se apresentam de forma incompleta e inconclusivas, pois é necessário no mínimo de quatro a cinco dentes para uma análise confiável (Chugh \& Narwal, 2017). A complexidade dessas lesões e sua interpretação podem representar um trabalho dificultoso até mesmo para os dentistas forenses mais experientes (Hinchliffe, 2011).

O tempo de coleta de evidências é extremamente curto, pois se passar um período muito longo desde o momento da lesão até o momento da descoberta, podem haver alterações no ferimento, tornando a evidência ainda mais imprecisa (Sweet \& 
Pretty, 2001). Outra questão relevante, refere-se às fraudes nos registros fotográficos que podem ocorrer. Neste contexto, medidas de precaução devem ser tomadas como a marcação d'agua das imagens digitais, para evitar a reutilização maliciosa (Chowdhry et al., 2014).

\section{Discussão}

Diante de tantas subjetividades, essa análise acaba sendo, por diversas vezes, contestada, dividindo opiniões entre os autores. Alguns sustentam que a técnica é eficaz, e pode ser usada nos processos forenses, já outros, questionam a individualidade das marcas de mordida e preconizam seu uso apenas para a inclusão ou exclusão de suspeitos (Barsley et al., 2018).

Tais divergências também se justificam pelo número de análises incorretas que foram notificadas no passado (Dama et al., 2020). A exposição desses erros nas Cortes Americanas fizera pessoas inocentes serem indiciadas e, consequentemente, trouxe um certo receio aos profissionais forenses (Mânica, 2016).

Devido a essas controvérsias, se torna cada vez mais necessário a padronização e os treinamentos apropriados durante a execução dessas análises (Hinchliffe, 2011). A American Board of Forensic Odontology estabelece diretrizes para a padronização dessas análises, afim de regular e normatizar o trabalho do dentista forense (Verma; Kumar \& Bhattacharya, 2013).

O odontolegista se torna uma peça essencial dentro das ciências forenses, pois é ele quem detém o conhecimento necessário sobre anatomia dentária, radiologia odontológica, materiais odontológicos e dessa forma consegue atuar dentro de uma equipe multidisciplinar ajudando a acelerar as investigações (Nuzzolese et al., 2008).

A odontologia forense é um campo em expansão, e a presença de profissionais treinados e experientes se torna cada vez mais indispensável. A análise por meio das marcas de mordida pode ser um fator chave na revelação dos acontecimentos da cena do crime, ajudando o sistema judiciário a chegar no verdadeiro culpado (Verma; Kumar \& Bhattacharya, 2013).

Com as taxas de criminalidade sempre crescentes, a sociedade enfrenta novos desafios a cada dia perante a identificação de um criminoso. Mesmo com a tecnologia avançada, a investigação criminal demanda de uma série de disciplinas trabalhando em conjunto e recolhendo provas, para solucionar um crime (Kaleelullah \& Hamid, 2020).

Delitos que envolvem marcas de mordida, geralmente estão associadas a crimes de natureza muito grave, e se condenado, o indivíduo pode ser preso por vários anos. Diante de tamanha responsabilidade, o dentista forense deve fazer essa análise apenas quando houver evidências de alta qualidade, seguindo todos os protocolos e examinando todos os suspeitos para as devidas comparações (Hinchliffe, 2011). Os profissionais também devem ter um vasto conhecimento ao fazer o diagnóstico diferencial quando se depara com essas marcas, pois outros objetos ou até mesmo lesões dermatológicas podem deixar hematomas semelhantes às mordidas (Weeratna, 2014).

As inovações tecnológicas como as análises assistidas por computador, têm demonstrado resultados promissores, com um nível de confiabilidade maior do que os métodos tradicionais (Maji et al., 2018). Thali et al. (2003) demonstraram a importância dos métodos 3D através da utilização de um scanner de superfície. Este equipamento permitiu a confecção de um molde com características precisas e sem distorções, cujas imagens podem ser visualizadas na tela do computador.

Marques et al. (2013) e Ali, Sansare e Karjodkar (2018) aplicaram a Tomografia Computadorizada de Feixe Cônico para a análise de marcas de mordidas em alimentos e objetos, com essa técnica demonstraram que esse método é eficiente, preciso, e não gera distorções, tendo potencial de se tornar uma ferramenta para a análise de marcas de mordida em artefatos encontrados na cena do crime.

Pallam (2016) comparando quatros métodos diferentes (traçado manual de modelos de estudo, traçado manual de método de impressão de cera, método de impressão radiopaco de cera e método xerográfico), concluiu que elas apresentam 
resultados semelhantes, então a escolha depende da preferência pessoal, cirurgião-dentista quem deve definir qual técnica utilizar e qual técnica é a melhor para cada caso.

Além da análise, o dentista forense também deve ter conhecimento em estatística, para elaborar os laudos de uma forma clara e explicativa, evitando declarações vagas ou confusas nas cortes. Dessa forma, é possível notar que, as tecnologias não param de evoluir, e esse fator aliado aos profissionais especializados, tem a capacidade de revolucionar o campo da identificação humana, aprimorando cada vez mais a interpretação das provas forenses (Mânica, 2016).

\section{Conclusão}

É certo que a análise das marcas de mordida possui suas limitações e só deve ser usada quando existirem características únicas, que consigam distinguir o dono da arcada analisada. Apesar disso, é uma ferramenta notável da Odontologia Forense, podendo não só indicar possíveis suspeitos como também exonerar inocentes. Em uma sociedade onde infelizmente o número de crimes é crescente, aprimorar as pesquisas e incentivar os profissionais das ciências forenses se torna crucial.

Mediante o exposto, percebe-se que o dentista forense tem papel de destaque dentro das investigações, afinal é ele quem detém o conhecimento acerca de anatomia dentária para reconhecer se aquela marca foi realmente causada por uma mordida, e se ela possui detalhe suficiente para ser utilizada. Além disso, se for definido que ela pode ser aplicada como prova, é o profissional que irá definir qual técnica de comparação deverá ser empregada.

As marcas de mordida continuam sendo motivo de divergência devido às suas subjetividades, e é por isso que novas tecnologias vêm sendo desenvolvidas com o objetivo de minimizar as taxas de erro. Mas não basta apenas as tecnologias, é imprescindível a presença de um profissional capacitado dentro das equipes de investigação forense, pois ele poderá auxiliar de maneira ímpar nos processos de identificação humana, principalmente no que se refere aos estudos dos padrões das marcas de mordida.

\section{Referências}

Ali, I. K., Sansare, K., \& Karjodkar, F. R. (2018). Analysis of Intercanine Distance and Dimensional Changes in Bite Marks on Foodstuffs Using Cone Beam Computed Tomography. Am J Forensic Med Pathol., 39 (3), 213-217.

Almeida, C. A., Paranhos, L. R. \& Silva, R. H. A. (2010). A importância da odontologia na identificação post-mortem. Odontologia e Sociedade, 2 (2), 7-13.

Amorim, H. P. L., Melo, B. M. S., Musse, J. O., Silva, M. L. C. A., Costa, M. C. O. \& Marques, J. A. M. (2016). Levantamento de marcas de mordidas humanas em vítimas de violência periciadas no Instituto Médico Legal de Feira de Santana-BA, entre 2007 e 2014. Arquivos Odontologia, 52(3), 165-174.

Araújo, L. G., Recalde, T. S. F., Jacometti, V., Costa, P. B. \& Silva, R. H. A. (2019). Stability Analysis of Bitemarks in Different Conditions of Time and Temperature and Its Reliability as Evidence in Criminal Investigations. Brazilian Dental Journal, 30(3), $295-302$.

Ata-Ali, J. \& Ata-Ali, F. (2014). Forensic dentistry in human identification: A review of the literature. J Clin Exp Dent, 6(2), 162-7.

Avon, S.L. (2004). Forensic odontology: the roles and responsibilities of the dentist. Journal of the Canadian Dental Association, 10(7), 453-8.

Barsley, R. E., Bernstein, M. L., Brumit, P. C., Dorion, R. B. J., Golden, G. S., Lewis, J. M., Mcdowell, J. D., Metcalf, R. D., Senn, D. R., Sweet, D. \& Weems, R. A. (2018). Epidermis and Enamel: Insights Into Gnawing Criticisms of Human Bitemark Evidence. The American Journal of Forensic Medicine and Pathology, 39(2), 87-97.

Bhagat, S., Gupta, V., Tyagi, N., Sharma, E., Gupta, S. \& Dadu, M. (2018). Mohit. Berry's index: Adjuvant to bite marks. Journal Forensic Dental Science, $10(1), 45-49$.

Bush, M. A., Miller, R. G., Bush, P. J. \& Dorion, R. B. (2009). Biomechanical factors in human dermal bitemarks in a cadaver model. J Forensic Sci., 54(1), 167-76.

Coutinho, C. G. V., Ferreira, C. A., Queiroz, L. R., Gomes, L. O. G. \& Silva, U. A. (2013). O papel do odontolegista nas perícias criminais. RFO, 18(2), 217223.

Chowdhry, A., Sircar K, Popli, D. B. \& Tandon, A. (2014). et al. Image manipulation: Fraudulence in digital dental records: Study and review. J Forensic Dent Sci, 6(1), 31-5. 
Chugh, A. \& Narwal, A. (2017). Oral mark in the application of an individual identification: From ashes to truth. J Forensic Dent Sci, 9(2), 51-55.

Dama, N., Forgie, A., Mânica, S. \& Revie, G. (2020). Exploring the degrees of distortion in simulated human bite marks. Int J Legal Med, $134(3)$, $1043-1049$.

Divakar, K.P. (2017). Odontologia Forense: The New Dimension in Dental Analysis. International Journal Biomed Science, 13(1), 1-5.

Figueira Junior, E. \& Moura, L.C.L. D. A importância dos arcos dentários na identificação humana. Rev. bras. odontol.,71(1), $22-7$.

Franco, A., Willems, G., Souza, P.H., Bekkering, G. E. \& Thevissen, P. (2015). The uniqueness of the human dentition as forensic evidence: a systematic review on the technological methodology. Int J Legal Med., 129(6), 1277-83.

Golden, G.S. (2011). Standards and practices for bite mark photography. J Forensic Odontostomatol, 29(2), 29-37.

Hinchliffe, J. (2011). Forensic odontology, part 4. Human bite marks. British Dental Journal, 363-368.

Kaleelullah, R. A. \& Hamid, P. (2020). Forensic Odontology, a Boon and a Humanitarian Tool: A Literature Review. Cureus, 12(3), 7400.

Kapoore, P. \& Chowdhry, A. (2018). Salivary signature in forensic profiling: A scoping review. J Forensic Dent Sci, 10(3), $123-127$.

Kashyap, B., Anand, S., Readdy, S., Sahukar, S. B ., Supriya, N. \& Pasupuleti, S. (2015) Comparison of the bite mark pattern and intercanine distance between humans and dogs. J Forensic Dent Sci, 7(3), 175-9.

Maji, A., Khaitan, T., Sinha, R, Sarkas, S., Verma, P. \& Shukla, A. K. (2018). A Novel Computer-Assisted Method of Bite Mark Analysis for Gender Determination. J Environ Public Health., 7130876.

Mânica, S. (2016). Difficulties and limitations of using bite mark analysis in Forensic Dentistry - a lack of science. Revista Brasileira de Odontologia Legal, $3(2), 83-9$.

Marques, J., Musse, J., Caetano, C., Corte-Real, F. \& Corte-Real, A. T. (2013). Analysis of bite marks in foodstuffs by computer tomography (cone beam CT)3D reconstruction. J Forensic Odontostomatol., 31(1), 1-7.

Mattos, L.G. O., Silva, T. G., Rocha, A. M., Dietrich, L. \& Andrade, C. M. O. (2021). Análise de mordida humana: revisão de literatura. Revista de Odontologia Contemporânea, 5(1), 9-16.

Nascimento, M. M., Sarmento, V. A., Beal, V. E., Galvão, L. C. C., \& Marques, J. A. M. (2012). Identificação de indivíduos por meio das marcas de mordida em alimentos utilizando a engenharia reversa e a prototipagem rápida: caso simulado. Arq Odontol, 48(3), $134-141$.

Nuzzolese, E., Lepore, M. M., Cukovic-Bagic, I., Montagna, F., \& Di Vella, G. (2008). Forensic sciences and forensic odontology: issues for dental hygienists and therapists. International dental journal, 58(6), 342-348.

Pallam, N. K., Boaz, K., Natrajan, S., Raj, M., Manaktala, N., \& Lewis, A. J. (2016). Computer-based method of bite mark analysis: A benchmark in forensic dentistry? Journal of forensic dental sciences, 8(1), 32-39.

Pretty, I. A., \& Hall, R. C. (2002). Forensic dentistry and human bite marks: issues for doctors. Hospital medicine, 63(8), 476-482.

Pretty, I. A., \& Sweet, D. (2001). A look at forensic dentistry--Part 1: The role of teeth in the determination of human identity. British dental journal, 190(7), 359-366.

Pretty I. A. (2008). Forensic dentistry: 2. Bitemarks and bite injuries. Dental update, 35(1).

Riaud X. (2014). Convicted by a bite mark, Ted Bundy (1946-1989). Dental historian: Lindsay Club newsletter, (59), 11-13.

Shah, P., Velani, P. R., Lakade, L., \& Dukle, S. (2019). Teeth in forensics: A review. Indian journal of dental research: official publication of Indian Society for Dental Research, 30(2), 291-299.

Sweet, D., \& Pretty, I. A. (2001). A look at forensic dentistry--Part 2: teeth as weapons of violence--identification of bitemark perpetrators. British dental journal, $190(8), 415-418$.

Thali, M. J., Braun, M., Markwalder, T. H., Brueschweiler, W., Zollinger, U., Malik, N. J., Yen, K., \& Dirnhofer, R. (2003). Bite mark documentation and analysis: the forensic 3D/CAD supported photogrammetry approach. Forensic science international, 135(2), $115-121$.

Tuceryan, M., Li, F., Blitzer, H. L., Parks, E. T., \& Platt, J. A. (2011). A framework for estimating probability of a match in forensic bite mark identification. Journal of forensic sciences, 56 Suppl 1, S83-S89.

Verma, A. K., Kumar, S., \& Bhattacharya, S. (2013). Identification of a person with the help of bite mark analysis. Journal of oral biology and craniofacial research, 3(2), 88-91.

Weeratna J. B. (2014). Are they dermatological lesions, bottle top burns or bite mark injuries? The Journal offorensic odonto-stomatology, 32(1), 1-8.

Whittaker D. K. (2004). Bite marks--the criminal's calling cards. British dental journal, 196(4), 237.

Zapico, S. C., \& Menéndez, S. T. (2016). Human mitochondrial DNA and nuclear DNA isolation from food bite marks. Archives of oral biology, 70, 67-72. 